\title{
Design and Construction of Automized Assembly Application
}

\author{
E. E. HTWE ${ }^{1}$, S. HATANAKA ${ }^{2}$ AND T. AKIYAMA ${ }^{2}$ \\ ${ }^{1}$ Mechanical Engineering Department, Mandalay Technological University, \\ Patheingyi Township, Mandalay, Myanmar \\ 23-2-30 Itakano Higashi-yodogawaku, Osaka-shi, 533-0001, Japan
}

\begin{abstract}
Nowadays the main stream of current automatic process and assembly is on intermittent transportation. Robot control systems can be divided into motion control and force control depending on the work. Assembly work is necessary to consider the state of force applied by detection of the force or moment on the fingers of the gripper. In this project, four groups designed and developed each one of the stages of the workpieces until the final piece was delivered; it was composed of three different workpieces. The mechanism was designed to set the shaft and fasten the screw into a vacancy in a workpiece. The machine was constructed with frame, base plate, support, gripper and workpieces by using CNC milling, turning, drilling and wirecut machine. This paper briefly describes the design analysis of a conveyor, actuator and motor control system.
\end{abstract}

Key words: Assembly; control; feeding; fastening; updown; design analysis; bearings

With the advances in electronics in recent years, industrial robots are finally coming into practical use, well supported by advanced hardware and software technology. The main considerations of this project were purpose of use, size of the object to be conveyed, the speed of the conveyance and positioning accuracy.

The project was to make a bearing assembly with two different materials. Since it had two different kinds of workpiece, two stations were needed for the machine. The first station was designed coloured workpieces, the other one designed non-colour pieces. Before reading the colour or non-colour workpiece by the colour sensor, four workpieces were placed inside the ordinary station in group one. As soon as the condition started, the first workpiece advanced on the conveyor, moving by cylinder action. After the colour sensor had read the workpiece colour, it sent a ready signal to group two.
After group two had received a ready signal from group one, the conveyor belt start to move. At the end of the conveyor, the workpiece stopped by the sensor and a gripper picked and placed it on the conveyor of group two. If work piece (1) was coloured as detected by the photo electric sensor, the first stopper's advance and work piece (1) was stopped at this station and conveyor belt stopped to move only later. Colour workpiece (2) was inserted to workpiece (1) by pneumatic cylinder.

After the pneumatic cylinder retracted, the stopper retracted and the conveyor belt started to move. After the second stopper advanced, workpiece (1) stopped at this station and sent a ready signal to group three for the screw process. After the screw process was completed, it received a ready signal from group three and the second stopper retracted, the conveyor belt moved and at the same time it sent a ready

* Corresponding author (e-mail: eieihtwe.mdy2012@gmail.com; dr.kyawsein@gmail.com; dan@kansai.interq.or.jp) 
signal to group four for the rotating table and the conveyor belt to move.

If the workpiece was a non-coloured one after detection by the photo electric sensor, the second stopper advanced and a certain time later, the conveyor stopped. At this position, when workpiece (1) stopped at the second station, workpiece (2) was inserted to workpiece (1) by pneumatic cylinder. The pneumatic cylinder retracted and sent a ready signal to group three for the screw process. After the screw process was completed, a ready signal was received from group three and the second stopper retracted the conveyor belt moved. At the same time group 2 sent a ready signal to group four for the rotating table and conveyor to move. Finally, different assembly workpieces were sent to the storage stacker according to colour or non-colour workpiece, by sensor.

Automatic Machine Making Procedure

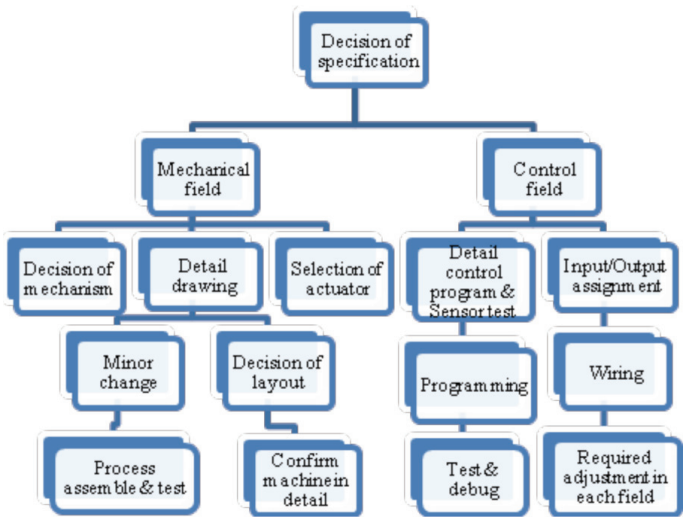

Figure 1. Flow diagram of automatic machine.

\section{Operation and Requirement of Part List (Group 1)}

This paper briefly considered how to make a section of an automatic machine to act out a sorting-out and delivery rule. It consisted of a rotary actuator, a gripper, cylinder, induction motor, belt, roller and aluminum frame.
A rotary actuator sent the workpiece to Group 2 and a gripper was used for clamping the workpiece. The cylinder pushed the workpiece to the conveyor which was driven by an induction motor. A belt was used to convey the workpiece and two rollers were used for belt rotation. All the parts mentioned above were put together and most of the frame components were machined by using the wirecut and $\mathrm{CNC}$ machining centre.

\section{DESIGN ANALYSIS}

First, an induction motor without brakes was selected to drive the belt conveyor. The mass of workpiece had to be identified for choosing a double acting cylinder. According to the results of cylinder tube bore, it was possible to get the stroke length for the feeder part.

\section{Selection of the Induction Motor to Drive the Belt Conveyor}

Design parameters to select the induction motor:

$\begin{array}{ll}\text { Mass of } 1 \mathrm{st} \text { workpiece }(\text { Aluminum) } & =58 \mathrm{~g} \\ \text { Mass of } 2 \mathrm{nd} \text { workpiece }(\text { Aluminum) } & =3.9 \mathrm{~g} \\ \text { Mass of screw }(\text { Steel) } & =5.2 \mathrm{~g} \\ \text { Total weight of workpiece } & =67.1 \mathrm{~g}\end{array}$

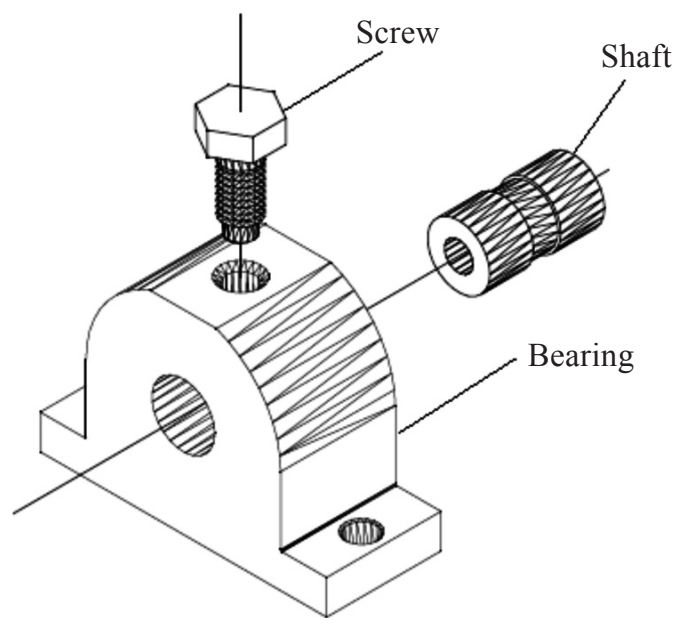

Figure 2. Bearing workpiece for assembly operation. 
Flat Belt Type,

Thickness, length, width (mm): 0.9, 1100, 30

Drive pulley:

$\varnothing 40 \mathrm{~mm}$

Weight: $1 \mathrm{~kg} / \mathrm{m}^{2}, 33 \mathrm{~g}$

Allowable stress:

$4.0 \mathrm{~kg} / \mathrm{cm}^{2}$

Total mass of belt \& workpiece: $\mathrm{W}=100.1 \mathrm{~g}$

Friction coefficient of sliding surface: $\mu=0.3$

Drum radius:

$\mathrm{D}=30 \mathrm{~mm}$

Belt roller efficiency:

$\eta=0.9$

Belt speed:

$\mathrm{V}=60 \mathrm{~m} / \mathrm{sec}$

Gearhead transmission efficiency, $\eta_{\mathrm{G}}=0.66$

Motor power supply:

Single phase

$110 \mathrm{~V}, 60 \mathrm{~Hz}$

\section{Determining the Gearhead Reduction}

Ratio:

$$
N_{G}=\frac{60 V}{\pi D}
$$

Since the rated speed for the induction motor at $60 \mathrm{~Hz}$ was $1200 \mathrm{rev} / \mathrm{min}$, the gearhead reduction ratio i was calculated as follows:

$$
i=1200 / N_{G}
$$

The nearest available gear ratios on catalogue were 30 and 36 , but 36 was selected for the speed.

\section{Calculating the Required Torque}

On a belt conveyor, maximum torque was needed to start the belt to move. To calculate the torque needed for starting, the friction force F of the sliding surface was firstly determined:

$$
F=\mu W
$$

Load torque $T_{L}$ was then calculated by:

$$
T_{L}=\frac{F D}{2 \eta}
$$

The load torque obtained was actually the load torque at the gearhead drive shaft, so that value was be converted into load torque at the motor output shaft. If the required torque at the motor output shaft was $T_{M}$ :

$$
T_{M}=\frac{T_{L}}{L \eta_{G}}
$$

Therefore, a motor OIK1GN _ AUL was the best choice. Since the reduction ratio 36 was required, gearhead OGN 36KA was connected to the OIK1GN_AUL motor.

\section{Choosing Double Acting Cylinder for Feeder Part}

Friction $\mu=0.28$

Operating pressure $=0.4 \mathrm{MPa}$

$$
\begin{aligned}
& F_{1}=(\mu W)_{4}+(\mu W)_{5} \\
& F=F_{1} \times 2(\text { For safety) }
\end{aligned}
$$

Where, $W_{4}, W_{5}=\frac{\text { Number of 1st workpiece }}{\text { Weight }}$

According to $\mathrm{P}_{-} \mathrm{O} 17$ Graph 1, when the load factor $=0.5$ and we could use 15, 30, 45, 60 stroke lengths from the catalogue for diameter 6 , we selected $45 \mathrm{~mm}$ stroke for the feeder part. (CDJ2B6-45R-H7NWL)

For stopping workpiece (Determining the Gearhead Reduction)

Weight of stopper $=2.7 \mathrm{~g}$

As a second to stop workpiece (Determining the Gearhead Reduction), we chose a double acting cylinder with stroke length $30 \mathrm{~mm}$ and diameter $6 \mathrm{~mm}$. (CDJ2B6 -30R - H7NW)

\section{Select a Rotary Actuator}

Specifications of design parameters:

Mass of Lever, $m_{1}=0.0323 \mathrm{~kg}$

Lever's inertia, $I_{1}=\frac{m_{1} L^{2}}{3}$ 


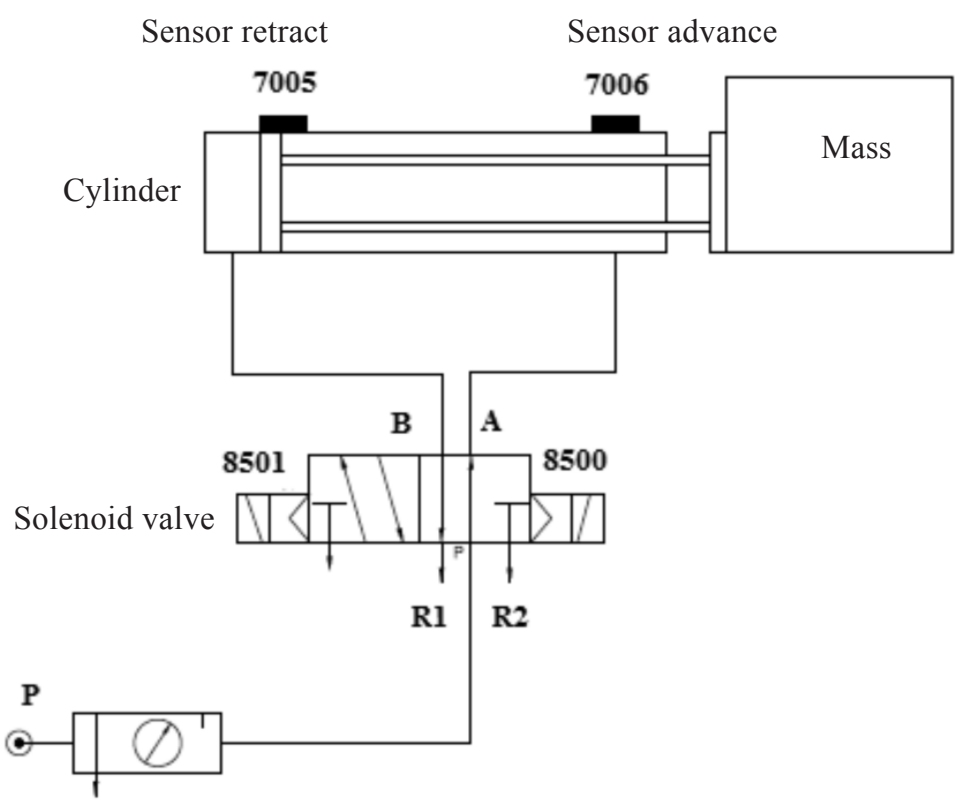

FRL unit

Figure 3. Pneumatic circuit for cylinder.

Gripper's inertia,

$$
I_{2}=m_{2}\left[\frac{a^{2}+b^{2}}{12}\right]+m_{2} L^{2}
$$

Workpiece's inertia,

$$
I_{3}=m_{3}\left[\frac{a^{2}+b^{2}}{12}\right]+m_{3} L^{2}
$$

Total inertia,

$$
I=I_{1}+I_{2}+I_{3}
$$

Load of inertia,

$$
T_{a}=I \omega
$$

Accelerating rate,

$$
\omega=\frac{2 \theta}{t^{2}}
$$

For safety, it needs to consider 10 times of load of inertia. So, CDRB1BWU 20-100-D-S79L rotary actuator was satisfactory for this project.

\section{RESULTS}

For Checking Allowable Shaft Load,

Total weight of lever + gripper + workpiece,

$$
\begin{aligned}
m & =140.3 \mathrm{~g} \\
F & =m a \\
& =1.372 \mathrm{~N}
\end{aligned}
$$
$F=1.372 \mathrm{~N}$ is smaller than vane style (double)

$$
\begin{aligned}
F_{r} & =\text { Lever Length } \times\left(W_{\text {gripper }}+W_{\text {workpiece }}\right) \\
& =85 \times(50+58) \\
& =9180 \mathrm{~g}-\mathrm{mm}
\end{aligned}
$$

$$
\begin{aligned}
\text { Load of inertia } & =F_{r} \times 9.81 \times 10^{-6} \\
& =0.09 \mathrm{Nm}
\end{aligned}
$$

$0.0122<0.09$ (satisfied)

So, CDRB1BWU 20-100-D-S79L rotary actuator is satisfactury for this project. 
Table 1. Design results of induction motor and actuator.

\begin{tabular}{l|cc}
\hline \multicolumn{1}{c|}{ Induction Motor } & Result & Units \\
\hline Speed at gearhead output $\left(N_{G}\right)$ & 38.2 & $\mathrm{Rev} / \mathrm{min}$ \\
Gearhead ratio $(i)$ & 36 & - \\
Friction force $(F)$ & 30 & $\mathrm{~g}$ \\
Load torque $\left(T_{L}\right)$ & 500 & $\mathrm{~g}-\mathrm{mm}$ \\
Torque at motor output $\left(T_{M}\right)$ & 42.08 & $\mathrm{~g}-\mathrm{mm}$ \\
Actuator: & & \\
Lever's inertia $\left(I_{1}\right)$ & $7.78 \times 10^{-5}$ & $\mathrm{Kg}-\mathrm{m}^{2}$ \\
Gripper's inertia $\left(I_{2}\right)$ & $3.65 \times 10^{-4}$ & $\mathrm{Kg}-\mathrm{m}^{2}$ \\
Workpiece's inertia $\left(I_{3}\right)$ & $4.33 \times 10^{-4}$ & $\mathrm{Kg}-\mathrm{m}^{2}$ \\
Load of inertia $\left(T_{a}\right)$ & $1.22 \times 10^{-2}$ & $\mathrm{Nm}$ \\
\hline
\end{tabular}

According to the results, the load of inertia was needed to be considered at 10 times for safety and a smaller actuator was better. The shocks were considered to be at the rotating ends for selecting the rotary actuator.

\section{PERFORMANCE TEST}

There were three parts to distinguish in the mechanism which had the electric, pneumatic and electronic devices:
a. Feeder area
b. Updown area; and
c. Fastening area.

The application required low speed, concerning only the accuracy of the stroke. Due to the rotational inertia of the plates and screws, the size and capacity of the motor was small.

If a cam was used, it would be very complicate to calculate, design and construct the movement of the fastening unit. The stepping motor was a good alternative to solve such inconveniences, since the only requirement was to program the speed control and driver with the positions needed, disregarding how accurate it might be.

The fastening area had the task of fastening the screw into the main workpiece. A stepping motor was selected for the actuator for this part of the machine, it is selected because it could be driven to rotate to as many turns required to achieve the fastening process.

\section{Assembly Operation of Automatic Machine with Different Processes}

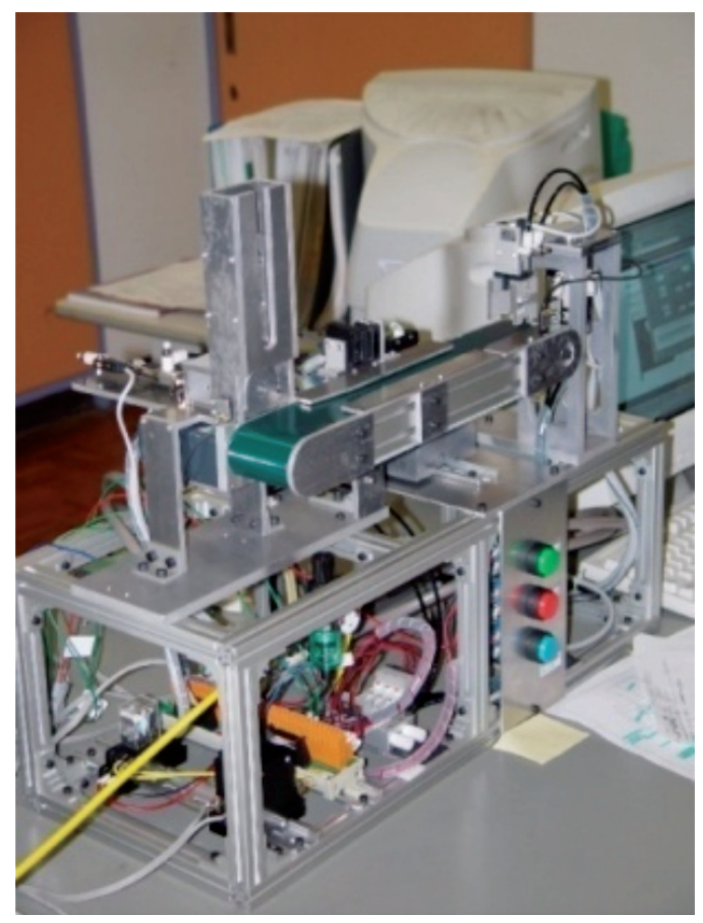

Figure 4. Feeding unit. 


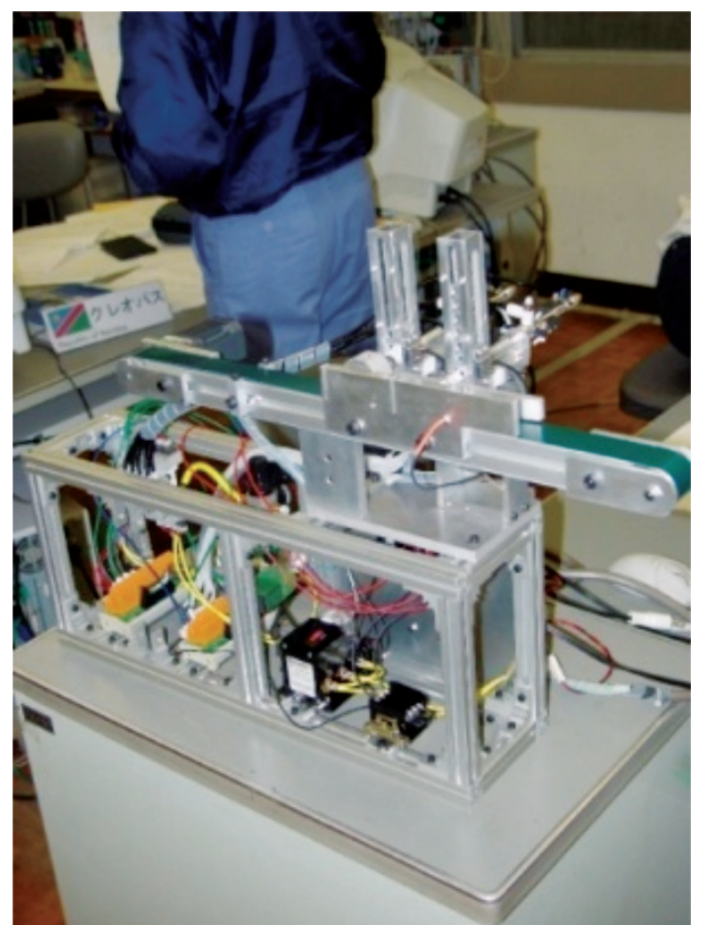

Figure 5. Colour or non-colour assembly.

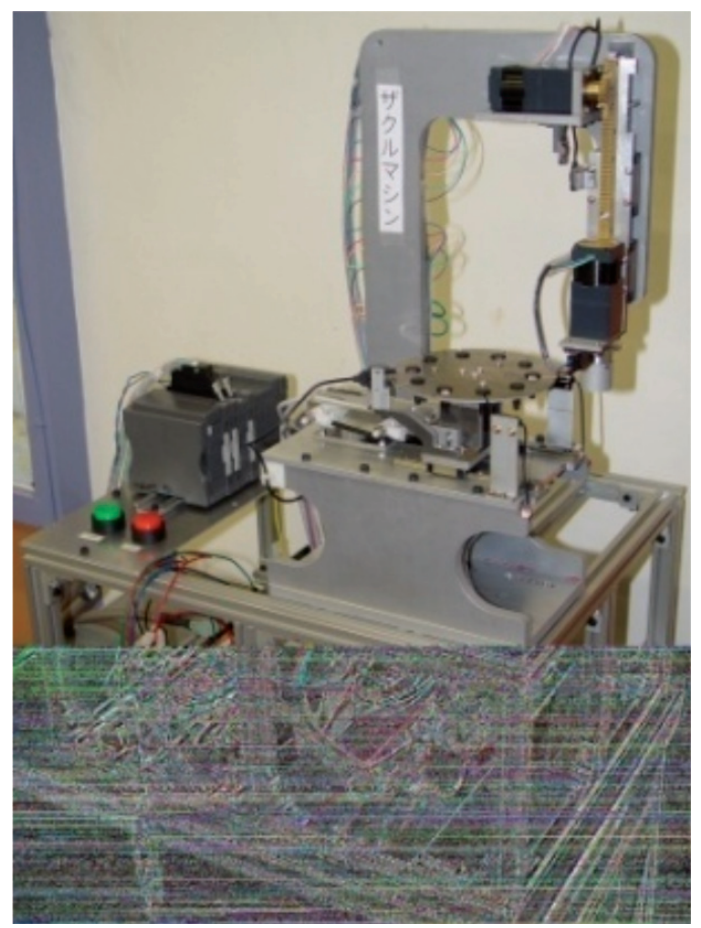

Figure 6. Updown and fastening unit. 


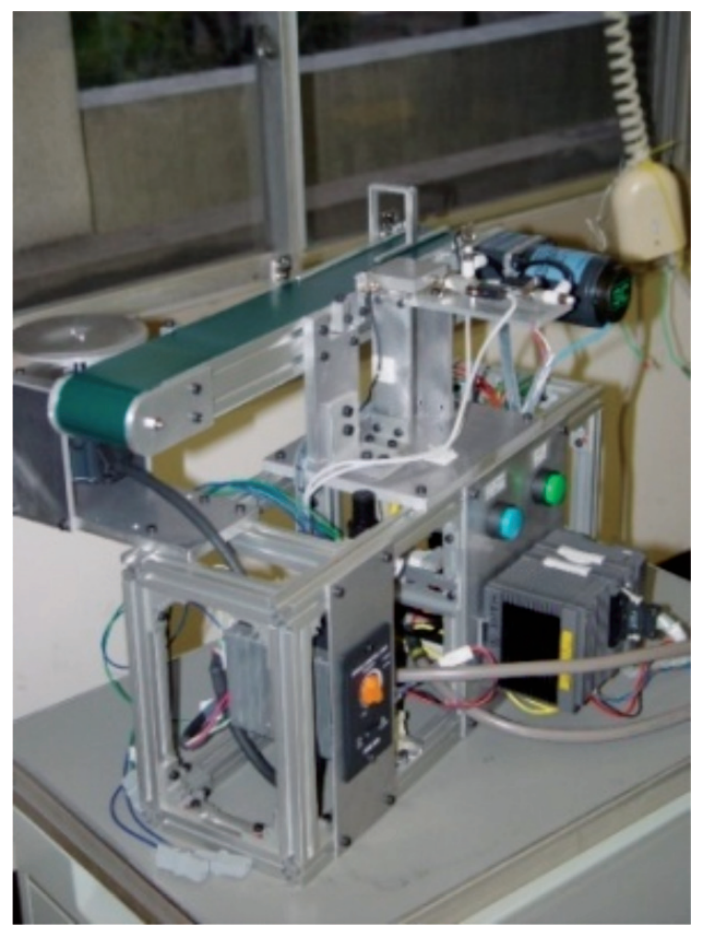

Figure 7. Colour or non-colour storage unit.

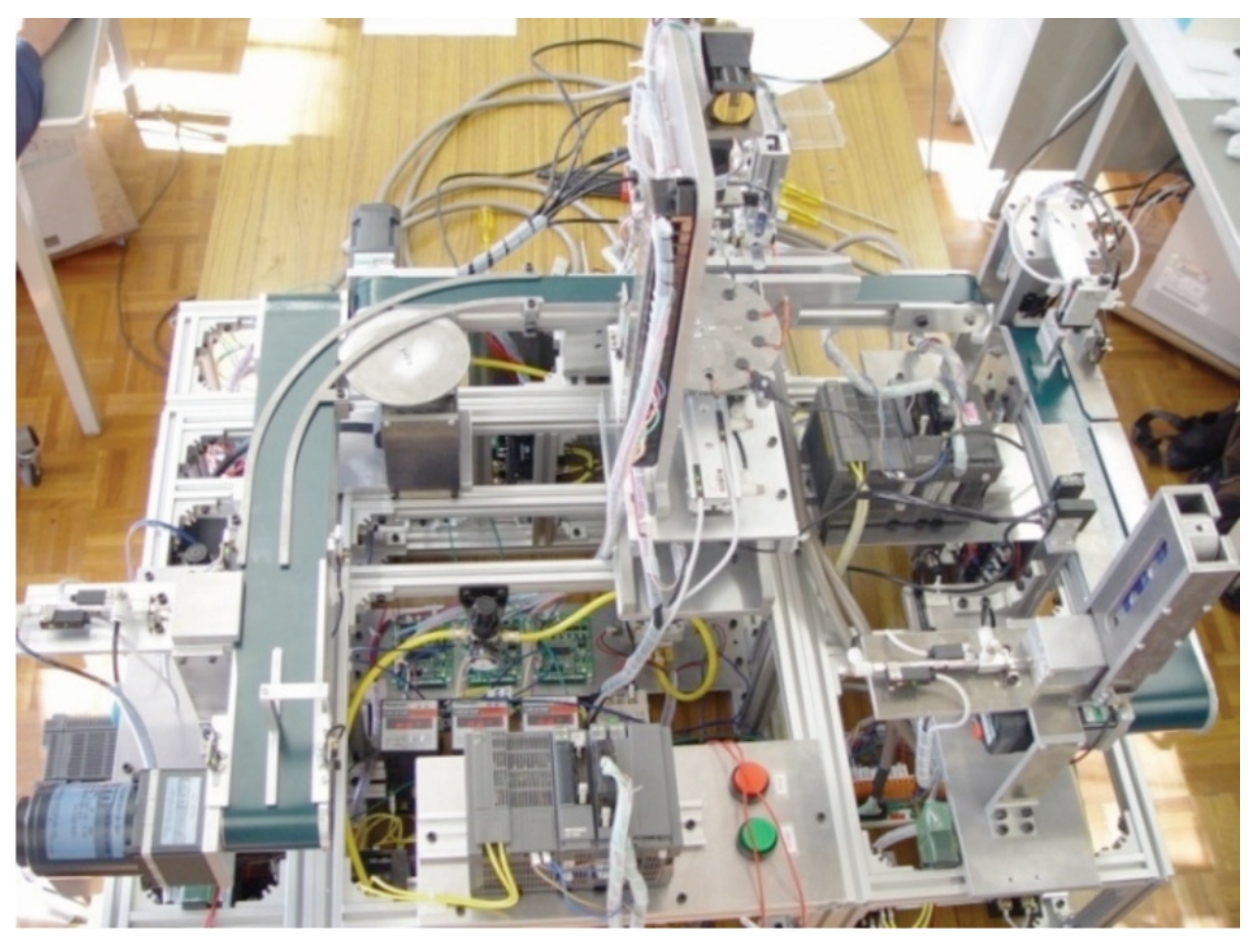

Figure 8. Bearing assembly with automatic machine. 


\section{Difficult Points on the Machine}

At difficult points on Group four were guides which were in the form of arcs. They were used to determine the radius of the arc that connected the two conveyors together and they had to pass over the table at the same time.

The table was in the space of $90^{\circ}$ that was formed by the two conveyors and it was almost equidistant to each conveyor. With the help of the Autocad, the two belt conveyors which formed a $90^{\circ}$ angle and a $8 \mathrm{~mm}$ gap between two conveyors were drawn.

\section{Input /Output Assignment (Group1)}

\begin{tabular}{|c|c|c|}
\hline $\mathrm{CH}$ & In & Out \\
\hline 00 & Cylinder retract sensor & Cylinder retract \\
\hline 01 & Cylinder advance sensor & Cylinder advance \\
\hline 02 & $\begin{array}{l}\text { Rotary actuator G1 } \\
\text { side sensor }\end{array}$ & $\begin{array}{l}\text { Rotary actuator } \\
\text { G1 side }\end{array}$ \\
\hline 03 & $\begin{array}{l}\text { Rotary actuator G2 } \\
\text { side sensor }\end{array}$ & $\begin{array}{l}\text { Rotary actuator } \\
\text { G2 side }\end{array}$ \\
\hline 04 & Gripper open sensor & Gripper open \\
\hline 05 & Gripper close sensor & Gripper close \\
\hline 06 & $\begin{array}{l}\text { Photoelectric sensor } \\
\text { for workpiece }\end{array}$ & Motor on \\
\hline 07 & $\begin{array}{l}\text { Photoelectric sensor } \\
\text { for middle position }\end{array}$ & $\begin{array}{l}\text { Send signal to } \\
\text { G2 start }\end{array}$ \\
\hline 08 & colour sensor & Workpiece colour \\
\hline 09 & $\begin{array}{l}\text { Photoelectric sensor } \\
\text { for end position }\end{array}$ & \\
\hline 10 & Start button & \\
\hline 11 & Reset button & \\
\hline 12 & $\begin{array}{l}\text { Continuous operation } \\
\text { button }\end{array}$ & \\
\hline 13 & Signal from G2 ready & \\
\hline
\end{tabular}

\section{CONCLUSION}

The machine was created using the Mechatronics field as a sorting-out and delivery machine. It consisted of a motor to move the conveyor and table, belt, frame and roller with shaft; two pair of sensors and plates for each group. Most of the parts were machined by using Autocad and wirecut. All the parts mentioned were assembled together to form the machine. The function of the machine was quite simple but it was very important for the smooth operation of the whole robot. There was no doubt that the machine would perform depending on the availability of all the components and the correct set control program.

\section{ACKNOWLEDGEMENT}

The financing of this project was provided by JICA Association and is gratefully acknowledged. The author of this paper would also like to thank members of the monitoring project advisory group: Sadao Hatanaka, Takahiro Akiyama and Kae Chogin. The author deeply thank the rector of Mandalay Technological University and her instructor Dr. Kyaw Sein, Professor of School of Mechatronic Engineering, University Malaysia Perlis (UniMap). The author is deeply grateful to her dear parents for their moral support, patience and encouragement throughout her whole life.

Date of submission: December 2011 Date of acceptance: June 2012

\section{REFERENCES}

Kobayashi, K 1994, Mechatro 1 3, Overseas Vocational Training Association (OVTA).

Miyamoto, K 1994, Machining Center, Numerically Controlled Series Machine Tool.

Akabane, N 1993, Pneumatic Sequence Control, Series 1 3, Polytechnic Center, Tochigi, Japan.

SMC Corporation, PneumaticTechnology, Shimbashi, Minato-ku, Tokyo, Japan.

Takada, Y 1994, NC Lathe, Numerically Controlled Series Machin Tool, Polytechnic College, Isikawa.

Kimura, Y 1996, Programmable Logic Controller, Toyama Polytechnic Center.

Isoyama, Y 1994, Sequence Control, Kimitsu Polytechnic Center. 